\title{
PRIMIGRAVIDAS; \\ FREQUENCY OF DIFFERENT MODE OF DELIVERIES AND ASSOCIATED MATERNAL COMPLICATIONS
}

1. MBBS, FCPS

Assistant Professor

Department of Gynecology and Obstetrics,

Isra University Hospital Hyderabad.

2. MBBS, FCPS Registrar,

Gynecology and Obstetrics,

Liaquat University Hospital,

Hyderabad.

Correspondence Address:

Dr. Sarwat Memon

Assistant Professor

Department of Gynecology and

Obstetrics, Isra University

Hospital Hyderabad.

dr.sarwat_memon@hotmail.com

Article received on:

09/09/2016

Accepted for publication:

$15 / 12 / 2016$

Received after proof reading:

$14 / 02 / 2017$

\section{Dr. Sarwat Memon', Dr. Sumaira Rauf ${ }^{2}$}

\begin{abstract}
Objectives: To determine frequency of different mode of deliveries and associated maternal complications in primigravidas in tertiary care setup. Study Design: Case series study. Setting: Department of Obstetrics and Gynaecology (Liaquat University Hospital) Hyderabad, Sindh, Pakistan. Period: 6 months from Jan 2009 till June 2009. Methodology: All the primigravidas underwent delivery by any means i-e emergencylelective caesarean section or spontaneous vaginal deliverylinstrumental vaginal delivery and developed postpartum complications up till 7 days after delivery were included. Data was analyzed on pre- designed profoma and was analyzed through software program SPSS version 10. Results: In this study most frequent mode of delivery were found to be spontaneous vaginal delivery $46(36.8 \%)$ and emergency caesarean section $29(23.2 \%$ ) while forceps $8.8 \%$, vacuum $20 \%$ and elective caesarean section $1.2 \%$. Complications associated with mode of deliveries included postpartum hemorrhage were reported to be $51.2 \%$, abdominal wound infection $11.2 \%$, perineal wound infection $17.6 \%$, retained products of conception $28 \%$ and puerperal sepsis $16.8 \%$. Conclusion: Deliveries in our setup are mostly conducted by dais (birth attendants) without any aseptic measures and without assessing the abnormalities that will leads to emergency caesarean section or instrumental vaginal deliveries and in the consequence of these entire patients develop postpartum complications.
\end{abstract}

Key words: Spontaneous vaginal delivery, Primigravidas, Perineal wound infection

Article Citation: Memon S, Rauf S. Primigravidas; frequency of different mode of deliveries and associated maternal complications. Professional Med J 2017;24(2):258262. DOI: $10.17957 / T P M J / 17.3630$

\section{INTRODUCTION}

The optimal mode of delivery is spontaneous vaginal delivery with both caesarean section and instrumental vaginal delivery. ${ }^{1}$ Spontaneous vaginal delivery is considered as preferred outcome of pregnancy because of perceived health, economic and social benefits derived from vaginal deliveries. ${ }^{2}$ Maternal satisfaction with vaginal delivery is high in those who experienced both mode of deliveries and prefer vaginal birth for future pregnancies ${ }^{3}$ but on the same time caesarean section has definitive valuable place in obstetrics due to life saving value for both mother and fetus. ${ }^{4}$ The incidence of caesarean section in tertiary care hospital of Pakistan is about 30$35 \% .{ }^{5}$ In nulliparous patients caesarean section accounts for $61-92 \%$ cases while $52-71 \%$ are normal vaginal deliveries. ${ }^{6}$

Caesarean section and force deliveries are common in primi patients than multips. ${ }^{11}$ Most common indications for first caesarean section were dystocia $42.8 \%$ cases, abnormal presentation $32.1 \%$ and fetal distress 18.5 . \% cases. ${ }^{12}$ It is also seen that higher percentage of younger women $<20$ years in first caesarean section group showed to be a risk factor associated with it. ${ }^{13}$ Regarding parity $35 \%$ first caesarean section were primigravidas, so constitutes important risk factor for first caesarean section. ${ }^{14}$

Complications rate with elective and emergency caesarean section is $15-35 \%$ and $4-6 \%$ and with spontaneous vaginal delivery and instrumental vaginal delivery $40-45 \%$ and $50 \%$. Maternal morbidity outcome variables includes early and late postpartum hemorrhage, wound infection (abdominal and episiotomy) and puerperal febrile morbidity. ${ }^{16}$ In our setup majority times it occurs because deliveries conducted at home by 
traditional birth attendants and referred to tertiary care hospital with prolong labor/ obstructed labor in moribund conditions. ${ }^{1}$ Many re admissions after caesarean section is due to puerperal sepsis $13.2 \%$.

In vaginal deliveries postpartum hemorrhage is most common reason for readmission. ${ }^{19} 3-23.6 \%$ cases. ${ }^{7-8}$ It is estimated that 500 maternal deaths occur per 100,000 live births each year in Pakistan due to above factors. ${ }^{20}$

Hence, the purpose of the study was to find out most frequent mode of delivery and associated complications, so optimal measures must be taken to reduce mortality with particular mode of delivery in primigravida.

\section{MATERIAL AND METHODS}

The study was conducted at department of obstetrics and gynecology (Liaquat University hospital) Hyderabad Sindh for 6 months from Jan to June 2009. Singleton full term primigravidas after excluding co morbidities were included. All the selected patients were assessed for mode of delivery and caesarean section or vaginal delivery (spontaneous/instrumental) done by senior resident doctor on duty. All the patients were examined completely on day of discharge to exclude any complication and called for follow up on $7^{\text {th }}$ post partum/postoperative day.

Data was collected on pre-designed proforma with variables like age, booking status, mode of delivery and post-operative/postpartum complications .Results were analyzed by SPSS version 10 .

\section{RESULTS}

During the study period of 6 months 125 patients were delivered. 87(69.9\%) were un booked and $38(30.4 \%)$ were booked (Table-l). Among them $46(36.85 \%)$ gone through spontaneous vaginal delivery, forceps delivery was performed in $11(8.8 \%)$, vacuum in $25(20 \%)$, emergency caesarean section 29(23.3\%) and elective caesarean section in $14(11.2 \%)$ patients (TableII).

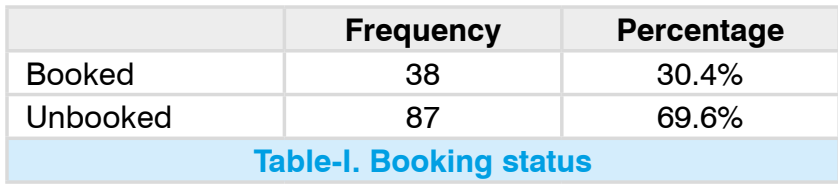

\begin{tabular}{|l|c|c|}
\hline \multicolumn{1}{|c|}{ Mode of delivery } & Frequency & Percentage \\
\hline Spontaneous Delivery & 46 & $36.8 \%$ \\
\hline Forceps Delivery & 11 & $8.8 \%$ \\
\hline Vaccum Delivery & 25 & $20.0 \%$ \\
\hline Emergency C-Section & 29 & $23.2 \%$ \\
\hline Elective C- Section & 14 & $11.2 \%$ \\
\hline Total & 125 & $100 \%$ \\
\hline \multicolumn{2}{|r|}{ Table-II. Frequency of mode of deliveries } \\
\hline
\end{tabular}

As far as age was concerned most primigravidas were between 21-30 years of age and most common mode of delivery was spontaneous vaginal delivery 31 patients(32.2\%) followed by emergency caesarean section 24 patients (25\%), vacuum $21(21.8 \%)$ cases. Elective caesarean section $11(14.4 \%)$ and forceps delivery least common mode of delivery $9.3 \%$ in this study (Table-III).

Most commonly seen complication was postpartum hemorrhage in 64(57.2\%) patients, wound infection (abdominal) in 14(11.2\%) whereas perineal in $22(17.6 \%)$ cases, retained product of conception was found in $35(28 \%)$ and puerperal sepsis in $21(16.8 \%)$ cases (Table-IV).

In relation of age to the complications, the most frequent age group that developed complications was 21-30 years. Out of 119 patients in the above mentioned group, 51 patients developed postpartum hemorrhage, 14 with abdominal wound infection and 16 with perineal wound infection, retained products of conception in 26 and puerperal sepsis in 12 patients (Table-V).

Frequency of complication with specific mode of delivery showed that postpartum hemorrhage developed in 22 patients with spontaneous vaginal delivery, in 6 patients with forceps, 12 patients with vacuum, 17 and 7 patients reported with elective and emergency caesarean section.

Abdominal wound infection was found in 10 patients with emergency and in 4 patients with 


\begin{tabular}{|l|c|c|c|}
\hline & \multicolumn{3}{|c|}{ AGE } \\
\hline Mode of deliveries & $\mathbf{1 7 - 2 0}$ yrs & $\mathbf{2 1 - 3 0}$ yrs & $\mathbf{3} \mathbf{3 0}$ yrs \\
\hline Spontaneous Delivery & $08(50 \%)$ & $31(32.2 \%)$ & $07(53.8 \%)$ \\
\hline Forceps Delivery & $01(6.25 \%)$ & $09(9.3 \%)$ & $01(7.69 \%)$ \\
\hline Vaccum Delivery & $03(18.7 \%)$ & $21(21.8 \%)$ & $01(7.69 \%)$ \\
\hline Emergency C- Section & $02(12.5 \%)$ & $24(25 \%)$ & $03(23 \%)$ \\
\hline Elective C- Section & $02(12.5 \%)$ & $11(14.4 \%)$ & $01(7.69 \%)$ \\
\hline Total & 16 & 96 & 13 \\
\hline
\end{tabular}

\begin{tabular}{|l|c|c|}
\hline \multicolumn{1}{|c|}{ Complications } & Frequency & Percentage \\
\hline Post-partum Hemmorhage & 64 & $51.2 \%$ \\
\hline Wound Infection & & \\
\hline$\alpha . \quad$ Abdominal & 14 & $11.2 \%$ \\
\hline$\beta . \quad$ Perineal & 22 & $17.6 \%$ \\
\hline Retained Products of Conception & 35 & $28 \%$ \\
\hline Puerperal Sepsis & 21 & $16.8 \%$ \\
\hline Total & 125 & $100 \%$ \\
\hline
\end{tabular}

\begin{tabular}{|l|c|c|c|}
\hline \multicolumn{1}{|c|}{ Complications } & \multicolumn{2}{c|}{ AGE } & > 30yrs \\
\hline Post-Partum Hemmorhage & $\mathbf{1 7 - 2 0 ~ y r s}$ & $\mathbf{2 1 - 3 0}$ yrs & 06 (37.5\%) \\
\hline Wound Infection & $7(3.3 \%)$ & $51(42.8 \%)$ & 0 \\
\hline a. Abdominal & & & \\
\hline b. Perineal & 0 & $14(11.7 \%)$ & $01(6.25 \%)$ \\
\hline Retained Products of Conception & $05(23.8 \%)$ & $16(13.4 \%)$ & $04(25 \%)$ \\
\hline Puerperal Sepsis & $04(19 \%)$ & $26(21.8 \%)$ & $05(31.2 \%)$ \\
\hline Total & 21 & $12(10 \%)$ & 16 \\
\hline
\end{tabular}

elective caesarean section where as perineal wound infection was found in 7 patients with spontaneous vaginal delivery, 5 patients with forceps and in 10 patients with vacuum deliveries. Retained products of conception was found in 24 cases of spontaneous vaginal delivery, 4 cases each with forceps and vacuum while in 5 patients with emergency and 2 with elective caesarean section. Puerperal sepsis was seen in 12 cases of spontaneous vaginal delivery, 3 in forceps, 4 in emergency and 2 in elective caesarean section with no cases report with vacuum delivery (TableVI).

\begin{tabular}{|l|c|c|c|c|c|c|}
\hline \multicolumn{1}{|c|}{ Complications } & $\begin{array}{c}\text { Spontaneous } \\
\text { Vaginal }\end{array}$ & Forceps & vacuum & $\begin{array}{c}\text { Emergency } \\
\text { C-Section }\end{array}$ & $\begin{array}{c}\text { Elective } \\
\text { C-Section }\end{array}$ & Total \\
\hline Post-Partum Hemmorhage & 22 & 06 & 12 & 17 & 07 & 64 \\
\hline Wound Infection & & & & & & \\
\hline a. Abdominal & 0 & 0 & 0 & 10 & 04 & 14 \\
\hline b. Perineal & 07 & 05 & 10 & 0 & 0 & 22 \\
\hline Retained Products of Conception & 24 & 04 & 04 & 05 & 02 & 35 \\
\hline Puerperal Sepsis & 12 & 03 & 0 & 04 & 02 & 21 \\
\hline Total & 46 & 11 & 25 & 29 & 14 & 125 \\
\hline
\end{tabular}




\section{DISCUSSION}

In this study 125 primigravidas were included who developed complications in postpartum period. The best mode of delivery is always spontaneous vaginal delivery but due to specific indications sometimes interventions as operative deliveries (vacuum and forceps) and abdominal deliveries (elective and emergency caesarean section) needed and leads to maternal morbidity and mortality.

The percentage of different mode of deliveries in our study included, spontaneous vaginal delivery was $36.8 \%$, forceps $8.8 \%$, vacuum $20 \%$, elective caesarean section $23.2 \%$ and emergency caesarean section $11.2 \%$. These percentages are lower than study done by Benedetti et $\mathrm{al}^{12}$ on nulliparous patients which showed spontaneous vaginal delivery $8.1 \%$, forceps $82.6 \%$, vacuum $84.4 \%$, emergency caesarean section $80.5 \%$ and elective caesarean section $44.4 \%$.

One local study on operative delivery also showed higher percentage of forceps $82.6 \%$ and vacuum $61 \%$ then our study, whereas the study by Allen $\mathrm{VM}$ et $\mathrm{al}^{11}$ showed lower percentage of caesarean section then our study i-e 2.9-7.9\% emergency and elective caesarean section rate $8.5-11.3 \%$.

Post-partum complications contribute to lots of maternal morbidities and lead to short and long term sequel and even mortality. One of most common postpartum complication is postpartum hemorrhage that is in our study was $51.2 \% .22(34.3 \%)$ developed from spontaneous vaginal delivery, $6(9.3 \%)$ from forceps, $12(18.7 \%)$ by vacuum, $17(26.5 \%)$ and $7(50.0 \%)$ from emergency and elective caesarean section which is much higher than a study by Benedetti et $\mathrm{al}^{12}$ which showed $5(1.2 \%)$ cases of spontaneous vaginal delivery, 2(1.8\%) forceps, $1(1.1 \%)$ vacuum, $5(9.2 \%)$ in caesarean section in labor and $2(0.5 \%)$ caesarean section without labor group. Some other local studies showed higher number of postpartum hemorrhage then our study in emergency caesarean section group i-e 25 cases and no case seen in elective caesarean section ${ }^{13}$ Post-partum hemorrhage with instrumental vaginal delivery was seen in $10(7.3 . \%)$ cases. $^{14}$

Wound infections commonly found in anemic patients, patients with poor hygiene, prior infection, poor sterilization, improper technique and homeostasis. Abdominal wound infection was seen in $10(71.4 \%)$ cases in emergency and $4(28.5 \%)$ in elective caesarean section group.

\section{CONCLUSION}

Deliveries in our setup are mostly conducted by dais (birth attendants) without any aseptic measures and without assessing the abnormalities that will leads to emergency caesarean section or instrumental vaginal deliveries and in the consequence of these entire patients developed postpartum complications.

Copyright@ 15 Dec, 2016.

\section{REFERENCES}

1. Baloch S, Khaskheli M, Khushk IA, Sheeba A. Frequency of $2^{\text {nd }}$ stage intervention and its outcome in relation with instrumental vaginal delivery versus caesarean section. J Ayub Med Coll Abotabad. 2008; 20(1):87-90.

2. National institute of Health Caesarean child birth. Consensus development conference statement. September 22-24, $1980 . \quad \mathrm{http}: / /$ consensus.nih. gov/1980/1980 caesarean 027 html.htm.accessed. Febuary 13, 2008.

3. Dunn EA, O Herlihy C. Comparison of maternal satisfaction following vaginal delivery after caesarean section and vaginal delivery. Eur $\mathrm{J}$ Obstet Gynaecol Reprod Biol. 2005, jul121; (1):56-60.

4. Ali M, Ahmed M, Hafeez R. Maternal and fetal outcome; comparison between emergency caesarean section versus elective caesarean section. Professional Med J. 2005; 12(1):32-9.

5. Khaliq A, Mehmmod H, Zakia AL. Post operative maternal consequences of caesarean section. Ann King Edward Med Coll. 2005; 11:39-41.

6. Wax JR. Maternal request caesarean versus planned spontaneous vaginal delivery: Maternal morbidity and short term outcome. J Semiperi. 2006; 7(03):24752.

7. Chaabra P, Sharma AK, Tupil KA. Obstetric and neonatal outcome in women who live in urban resettlement area of Delhi, India: A cohort study. J Obstet Gynaecol Res. 2006; 32(6):567-73. 
8. Qazi GR, Akhter S. Obstetrical correlates of the first time caesarean section compared with the repeated caesarean section. JCPSP. 2007; 17(10):611-4.

9. Zanetta G, Tampieri A, Currado I, Regalia A, Nespoli A, Midwife $T$ et al. Changes in caesarean delivery in an Italian university hospital,1982-1996: a comparison with the national trend. Birth; 1999:26:144-8.

10. Mesleh RA, Asiri F, Al-Naim MF. Caesarean section in primigravid. Saudi Med J. 2000; 21:957-9.

11. Allen VM, Connell CM, Liston RM, Baskett TF. Maternal morbidity associated with caesarean section without labor compared with spontaneous onset of labor at term. Obstet Gynaecol. 2003; 102:477-82.

15. Benedetto C Marozio L, Praudi G, Roccia A et al. Short term maternal and neonatal outcomes by mode of delivery. A case control study. Ejogrb. 2007; 135:35-40.

16. Ashraf R, Gul A, Bashir A, Tajamul A. Comparison of maternal complications in elective versus emergency caesarean section. Annals. 2006, Apr/Jun; 12(2):28890.

17. Akhter Y, Chohan MA. Primary postpartum hemorrhage after vaginal birth: an analysis of risk factors. Annals. 2006; 12(02):210-11.

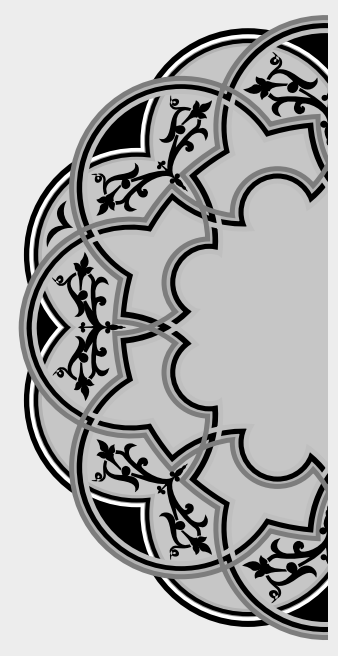

\title{
“Don't lose hope.
} You never know what tomorrow may bring."

\author{
Unknown
}

AUTHORSHIP AND CONTRIBUTION DECLARATION

\begin{tabular}{|c|l|l|}
\hline Sr. \# & \multicolumn{1}{|c|}{ Author-s Full Name } & \multicolumn{1}{c}{$\begin{array}{c}\text { Contribution to the paper } \\
\text { Author=s Signature }\end{array}$} \\
\hline 1 & Dr. Sarwat Memon & $\begin{array}{l}\text { Conceived the idea, Data } \\
\text { collection, Entey analysis } \\
\text { wrote the article } \\
\text { Technical input at every } \\
\text { step, editing overall } \\
\text { management }\end{array}$ \\
\hline Dr. Sumaira Rauf & &
\end{tabular}

